\title{
Cyclosporin inhibits hyperalgesia and edema in arthritic rats: role of the central nervous system
}

J.N. Francischi ${ }^{1}$ L.S.M. Pereira ${ }^{1}$ and M.S. Castro ${ }^{2}$

\author{
'Departamento de Farmacologia, Instituto de Ciências Biológicas, \\ Universidade Federal de Minas Gerais, 31270-010 Belo Horizonte, MG, Brasil \\ ${ }^{2}$ Departamento de Farmacodinâmica, Faculdade de Farmácia, \\ Universidade Federal de Minas Gerais, 30180-112 Belo Horizonte, MG, Brasil
}

\author{
Correspondence \\ J.N. Francischi \\ Departamento de Farmacologia \\ Instituto de Ciências Biológicas \\ Universidade Federal de \\ Minas Gerais \\ Av. Antonio Carlos, 6627 \\ 31270-010 Belo Horizonte, MC \\ Brasil \\ Fax: 55 (031) 441-0835 \\ E-mail: janettif@mono.icb.ufmg.br \\ Research supported by \\ CNPq (No. 520449/94-0), \\ FAPEMIG (No. CBS-1652/92) \\ and PRPq, MG, Brasil.
}

Received May 14, 1996

Accepted October 25, 1996

\begin{abstract}
Since arthritis induced by Mycobacterium products (adjuvant) in rats is considered to be immunologically driven, the objective of the present study was to determine if the immunosuppressor drug cyclosporin could affect hindpaw edema and joint hyperalgesia simultaneously. Female Holtzman rats (140-170 g) presented hyperalgesia and edema on the 8 th and 12 th day following adjuvant injection. Daily systemic (oral or intramuscular) administration of cyclosporin (0.5$\left.5.0 \mathrm{mg} \mathrm{kg}^{-1} \mathrm{day}^{-1}\right)$ or dexamethasone (0.01-0.1 mg kg${ }^{-1}$ day $\left.^{-1}\right)$ for 15 days starting on day zero dose-dependently inhibited the hindpaw edema and hyperalgesia in arthritic rats. However, hyperalgesia but not edema could be detected two days after cyclosporin withdrawal. We concluded that a) the continuous presence of cyclosporin is essential to reduce the development of joint hyperalgesia and that $b$ ) different mechanisms underlie the appearance of hyperalgesia and edema in this model. The intracerebroventricular (icv) administration of 5-50-fold smaller doses of cyclosporin (1.5-150 $\mu \mathrm{g} / \mathrm{day})$ or dexamethasone $(15 \mu \mathrm{g} / \mathrm{day})$ also reduced the arthritic hindpaw edema and hyperalgesia. Peripheral blood from animals injected with effective systemic cyclosporin doses showed detectable levels of the drug, whereas peripheral blood from those injected with $i c v$ cyclosporin did not, as measured by specific RIA. Our results indicate that cyclosporin administered by the central route is as effective as by the systemic route to reduce joint hyperalgesia and hindpaw edema in arthritic rats. The antiarthritic effect induced by low doses of cyclosporin in the central nervous system (CNS) could be explored to avoid its often associated systemic side effects during chronic therapy. However, the mechanism(s) involved in the antiarthritic response to cyclosporin in the CNS remain to be elucidated.
\end{abstract}

Key words

- Cyclosporin

- Hyperalgesia

- Edema

- Adjuvant arthritis 


\section{Introduction}

The rat adjuvant arthritis model has been widely used to study experimentally the pathophysiology of human rheumatoid arthritis because of the similarities between the two syndromes (1-5). This model has also proved to be a useful tool for investigating new analgesic and anti-inflammatory compounds $(6,7)$.

Experimental arthritis has been shown to be immunologically driven $(8,9)$, and immunosuppressive drugs such as cyclosporin (CsA) and rapamycin are known to affect its development $(10,11)$. The immunosuppressive action of cyclosporin and rapamycin has been associated with their ability to reduce the inflammatory hindpaw edema present in arthritic animals and with their capacity to interfere with normal T-cell functions. Both drugs inhibit the expression of a discrete set of lymphokines by promoting the binding of cytosolic proteins called cyclophilin and FK-binding protein (FKBP) to the corresponding genes. Extensive reviews of the action of cyclosporin and rapamycin have been provided by many authors (11-13).

Corticosteroids exert their anti-inflammatory and immunosuppressive effects primarily by interacting with cytosolic receptors (14) different from those for cyclosporin and rapamycin. In addition to regulating target gene expression, corticosteroids are also able to modify post-translational events and second messenger systems including the activity of phospholipase $A_{2}$ (15).

Using different approaches, we and others have shown that arthritic rats develop hyperalgesia (16-18). The objective of the present study was to determine whether the hyperalgesia of arthritic rats could be influenced by CsA administered either peripherally or into the central nervous system (CNS) of the animals. For comparison, dexamethasone, a standard anti-inflammatory drug, was tested in parallel.

\section{Material and Methods}

\section{Animals}

Female Holtzman rats (140-170 g) were used throughout this study. The animals were weighed every four days from day zero to the end of the experiments, always before any experimental procedure. Unless otherwise stated, the animals were kept in cages (maximum of 6 animals per cage) with water and food ad libitum, a temperature of $26 \pm 3^{\circ} \mathrm{C}$, and on a 12-h light-dark cycle.

\section{Induction of adjuvant arthritis}

Rats were injected subcutaneously with a single dose of $0.2 \mathrm{ml}$ mineral oil-water emulsion $(10: 1, \mathrm{v} / \mathrm{v})$ containing $400 \mu \mathrm{g}$ of dried Mycobacterium butyricum into the dorsal root of the tail under ether anesthesia. The time of adjuvant injection is referred to as day zero. Control rats received a subcutaneous injection of $0.2 \mathrm{ml}$ of the oil-water emulsion without bacilli on the same day.

\section{Measurement of articular hyperalgesia and hindpaw edema in rats}

The method for measuring hyperalgesia has been previously described (16). Briefly, the tendency of normal (naive), control and arthritic rats to vocalize following flexion of the tarsotibial joints of both hindpaws was tested daily for 22 days starting from day zero. The results are reported as the mean number \pm SEM of vocalizations obtained for five flexions per paw. Hindpaw volume (as an indicator of edema) was measured daily using an Ugo Basile hydroplethysmometer (model 7150) after the test for hyperalgesia. The volume ( $\mathrm{ml}$ ) of one hindpaw was essentially the same as that of the contralateral paw (data not shown) and is reported as the mean \pm SEM. All measurements were obtained at the same time of day. 


\section{Schedules for systemic and CNS drug administration}

Systemic administration. Various doses of cyclosporin $\left(0.5,2.5\right.$ and $5.0 \mathrm{mg} \mathrm{kg}^{-1}$ day $\left.^{-1}\right)$ or dexamethasone ( 0.01 and $0.1 \mathrm{mg} \mathrm{kg}^{-1}$ day $^{-1}$ ) diluted in sterile saline were administered by gavage $(1 \mathrm{ml} / 100 \mathrm{~g}$ animal) or intramuscularly (im, $0.1 \mathrm{ml} / 100 \mathrm{~g}$ animal) from day zero to the 14th day after induction of arthritis. All drugs were administered $2 \mathrm{~h}$ after the determination of hindpaw hyperalgesia and edema, except on day zero, when the drugs were administered $2 \mathrm{~h}$ before induction of arthritis. Control arthritic rats received the same volume of vehicle (diluted cremophor El or saline) administered by the same route.

CNS administration. The animals were prepared for intracerebroventricular (icv) injection under ketamine-xylazine anesthesia as used by Lemaire et al. (19). Metal cannulae were adapted from hypodermic needles (7-gauge) and fixed in a hole previously made in the exposed skull of each anesthetized animal. The stereotaxic coordinates used for cannulation were: anteroposterior, $-1.4 \mathrm{~mm}$, laterolateral, $-1.5 \mathrm{~mm}$ and vertical, 3.1 to $3.5 \mathrm{~mm}$ below the skull surface (20). The animals were housed in separate cages (one animal per cage) and arthritis was induced 4-5 days following the implantation of the cannulae, when the animals started to put on weight. Single doses of CsA $(1.5,15$ or $150 \mu \mathrm{g} / \mathrm{day})$ or dexamethasone (15 $\mu \mathrm{g} /$ day) diluted in sterile saline were cautiously injected into awake animals over a period of 15 days (final volume, $10 \mu \mathrm{l}$ ). The injections were performed using the free extremity of the fixed metal cannulae and occurred during a $30-\mathrm{sec}$ period. Control arthritic rats received an $i c v$ injection of 10 $\mu \mathrm{l}$ of diluted cremophor El (cyclosporin vehicle) or physiological saline instead of CsA or dexamethasone, respectively.

\section{Radioimmunoassay for cyclosporin in blood samples}

Blood (1-2 ml) was collected into EDTA tubes by cardiac puncture from ketaminexylazine-anesthetized arthritic rats, which were already receiving cyclosporin, on the 8 th or 12th day of treatment. Blood samples were also collected from two other groups of animals ( 2 rats/group) which had received 15 or $150 \mu \mathrm{g} / \mathrm{day} \mathrm{CsA}$, respectively, $4 \mathrm{~h}$ before. The blood samples were stored at $-15^{\circ} \mathrm{C}$ until assayed. Whole blood is the preferred sample for assay (21). The whole blood samples were assayed by radioimmunoassay (RIA) according to manufacturer instructions (Sandimmun kit, Sandoz, Santo Amaro, SP), using monoclonal antibodies specific for the form of cyclosporin injected. The ratio of RIA and high-performance liquid chromatography (HPLC) in whole blood was not significantly different from one (22). The limit of determination of the assay was $25 \mathrm{ng} / \mathrm{ml}$. Briefly, aliquots of $50 \mu \mathrm{l}$ of whole blood from all samples (standard, control, and unknown) were pretreated with $950 \mu \mathrm{l}$ methanol. Aliquots of the methanolic supernatant $(50 \mu \mathrm{l})$ were prediluted with buffer $(500 \mu \mathrm{l})$ and incubated with $\left[{ }^{3} \mathrm{H}\right]-\mathrm{CsA}$ and the specific monoclonal antibody for $2 \mathrm{~h}$ at $4^{\circ} \mathrm{C}$. Bound and free CsA were separated at $4^{\circ} \mathrm{C}$ after the addition of a charcoal suspension and centrifugation. Bound activity was measured in the supernatant by liquid scintillation counting (RackBeta, Beckman, Irvine, CA).

\section{Materials}

Mycobacterium butyricum powder was purchased from Difco (lot 43887JC, Detroit, MO). The following solutions were used: ketamine (Ketalar, Parke-Davies, AchéLaboratórios, SP), xylazine (Rompun, Bayer, $\mathrm{RS}$ ) and dexamethasone (Decadron, MSD, 
Prodome Química Farmacêutica, SP). Reagents for RIA and cremophor El were supplied by Sigma (St. Louis, MO) and cyclosporin (Sandimmun) and Sandimmun kit were a generous gift from Mr. Álvaro De Paoli from Sandoz, Santo Amaro, SP, Brazil.

\section{Statistics}

The results were analyzed by the onetailed Student $t$-test for single comparisons and one-tailed ANOVA for multiple comparisons with a control. $P$ less than 0.05 was
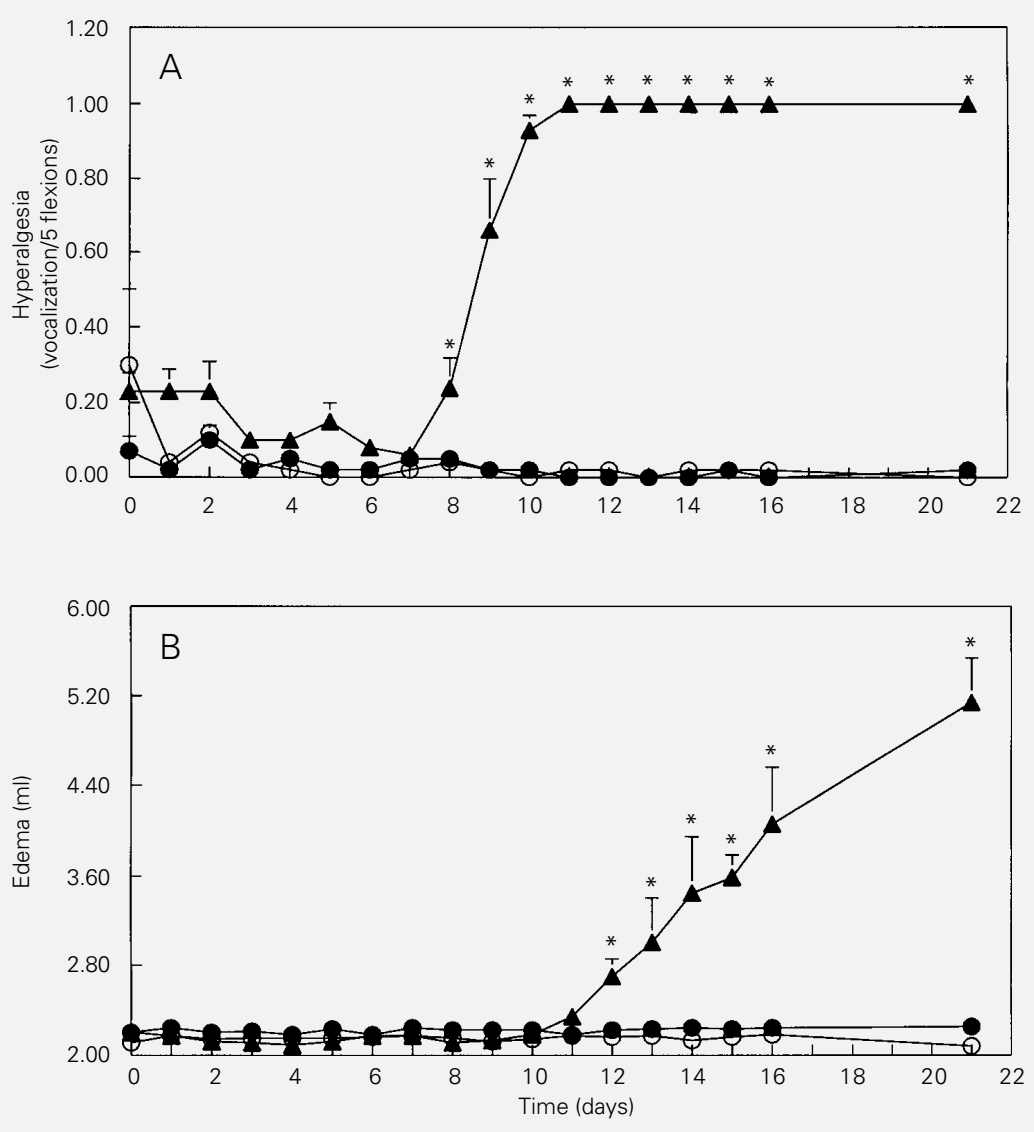

Figure 1 - Development of hyperalgesia (A) and edema (B) in arthritic rats. Arthritis was induced by the subcutaneous injection of $0.2 \mathrm{ml}$ of an emulsion containing $400 \mathrm{\mu g} \mathrm{Myco-}$ bacterium butyricum $(\mathbf{\Lambda})$ into the tail base of female rats on day zero. The reponses of control ( ) and normal (O) rats are also shown. The daily hyperalgesia measurements are reported as the number of vocalizations upon 5 flexions of the tibiotarsal joints of the animals (mean \pm SEM, $N=4-6$ ). Hindpaw edema was measured using an Ugo Basile hydroplethysmometer (model 7150). Hindpaw volumes are reported as the mean increase in volume $(\mathrm{ml}) \pm \mathrm{SEM}$. ${ }^{*} \mathrm{P}<0.05$ compared to naive or vehicle-treated animals (ANOVA $t$ test). considered to indicate statistical significance.

\section{Results}

To establish the initial experimental conditions, $400 \mu \mathrm{g}$ of $M$. butyricum (adjuvant) was injected into the dorsal root of the tail of ether-anesthetized rats. This dose induced a significant hyperalgesia in the hindpaw joints by the 8 th day after injection. The number of vocalizations ranged from $0.2 \pm 0.08$ to a maximum value of one (1.0) per five flexions of the paws on the 12th day of observation as compared with naive (non-injected) or control animals $(\mathrm{P}<0.05$; Figure $1 \mathrm{~A})$. Hyperalgesia remained elevated up to the $21 \mathrm{st}$ day of observation (Figure 1A) by which time the incidence of paw ankylosis was high $(35 \%)$ and precluded prolongation of the experiments (data not shown). The level of edema was significant by the 12th day after injection and resulted in a more than two-fold increase in the volume of both hindpaws by the 21 st day of observation, as illustrated for one of the hindpaws in Figure 1B. A dose of $200 \mu \mathrm{g}$ of M. butyricum did not induce significant hyperalgesia or edema (data not shown).

In order to determine the effect of cyclosporin in this model of arthritis and compare it with dexamethasone, various doses of both drugs were administered systemically to adjuvant-induced arthritic rats. Administration of cyclosporin $(0.5-5.0 \mathrm{mg}$ $\mathrm{kg}^{-1}$ day $\left.^{-1}\right)$ or dexamethasone $(0.01-0.1 \mathrm{mg}$ $\mathrm{kg}^{-1} \mathrm{day}^{-1}$ ) by the oral or im route dosedependently reduced both the joint hyperalgesia and hindpaw edema of arthritic rats (Figure 2A-D). An im $5 \mathrm{mg} \mathrm{kg}^{-1}$ day $^{-1}$ dose of cyclosporin completely blocked both the development of hyperalgesia and edema (Figure $2 \mathrm{~B}$ and $\mathrm{D}$, respectively) throughout the 15 days of administration. A significant reduction in hyperalgesia was also observed with the lowest oral dose of cyclosporin ( 0.5 $\mathrm{mg} \mathrm{kg}^{-1}$ day $^{-1}$; Figure 2A), although the same dose did not affect hindpaw edema to a 
similar extent (Figure 2C). Dexamethasone $\left(0.1 \mathrm{mg} \mathrm{kg}^{-1} \mathrm{day}^{-1}\right)$ administered either orally or im was virtually identical to cyclosporin $\left(5 \mathrm{mg} \mathrm{kg}^{-1} \mathrm{day}^{-1}\right)$ in reducing joint hyperalgesia and hindpaw edema in arthritic rats throughout the period of drug administration (Figure 2A-D). A lower oral dose of dexamethasone $\left(0.01 \mathrm{mg} \mathrm{kg}^{-1} \mathrm{day}^{-1}\right)$ was less effective in inhibiting the development of both arthritic indices (Table 1). However, following cessation of drug treatment, recurrence of hyperalgesia in the arthritic rats was more rapid for $0.1 \mathrm{mg} \mathrm{kg}^{-1}$ day $^{-1}$ dexamethasone than for $5 \mathrm{mg} \mathrm{kg}^{-1}$ day $^{-1}$ cyclosporin (Figure $2 \mathrm{~A}$ and $\mathrm{B}$ ). There was no recurrence of hindpaw edema at these doses after oral or im cyclosporin and dexamethasone administration (Figure 2C and D).

Since cyclosporin had inhibited joint hyperalgesia, we decided to determine the con- tribution of the central nervous system to this "analgesic" effect of the drug. I $c v$ administration of cyclosporin (1.5-150 $\mu \mathrm{g} / \mathrm{day})$ dose-dependently reduced joint hyperalgesia and hindpaw edema in arthritic rats (Figure 3). As with the systemic response this reduction was observed throughout the period of drug administration, and was most complete at the highest dose of cyclosporin used $(150 \mu \mathrm{g} / \mathrm{day}$, Figure $3 \mathrm{~A}$ and B). In addition, as in the case of systemic treatment, a significant level of hyperalgesia, but no edema, could be detected after terminating treatment with this dose of cyclosporin $(150 \mu \mathrm{g} /$ day, Figures $3 \mathrm{~A}$ and $3 \mathrm{~B})$. A shorter period of treatment ( 8 days starting from day zero) with $15 \mathrm{mg}$ of cyclosporin/day administered $i c v$ was also effective in inhibiting the hyperalgesia and edema in adjuvant-injected rats (Table 2). In this case, hyperalge-
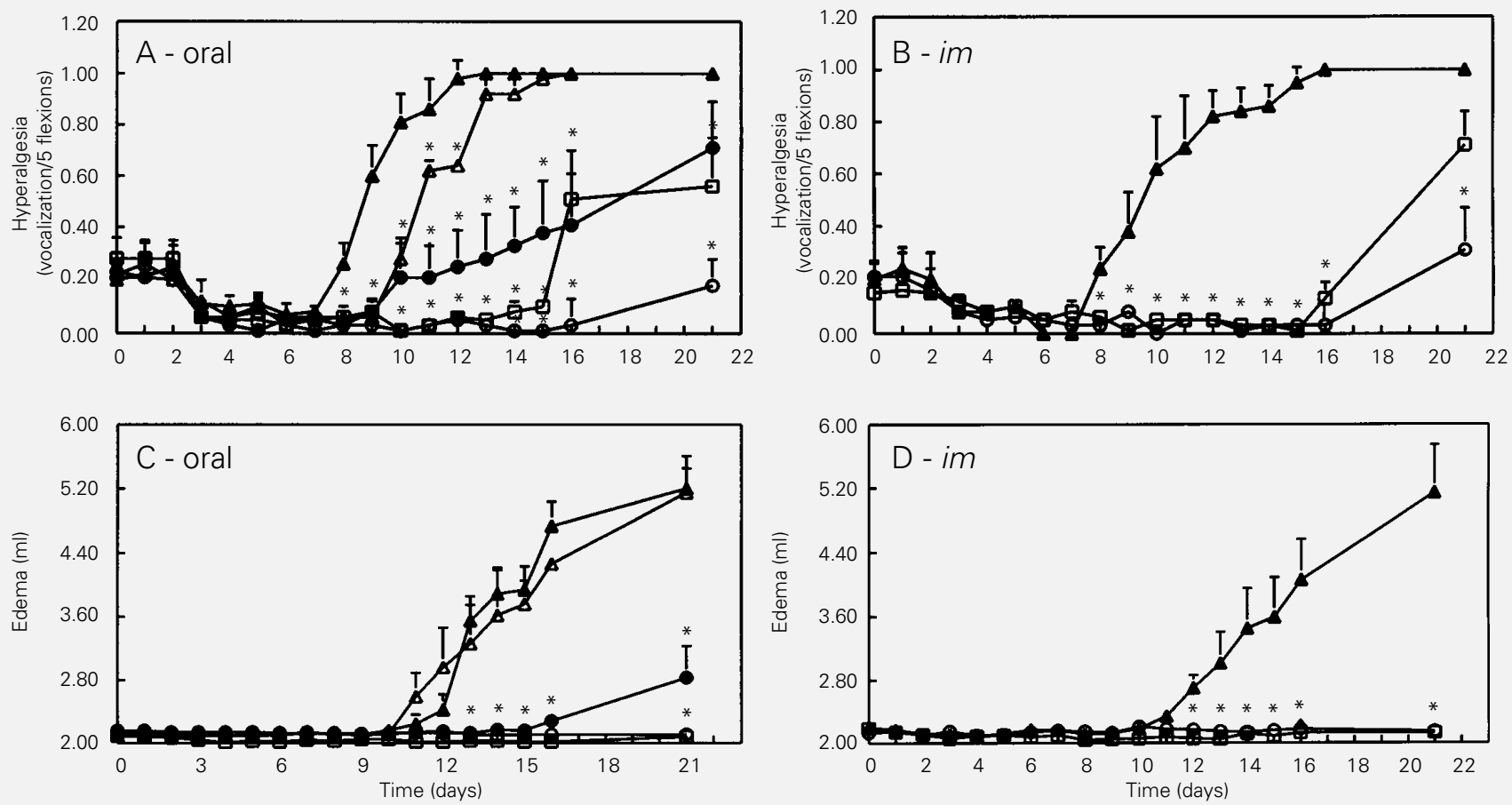

Figure 2 - Dose-response curves of cyclosporin administered im and orally on hyperalgesia (A and B) and edema (C and D) presented by arthritic rats. Cyclosporin ( ${ }^{\mathrm{a}}=0.5 ; \bullet=2.5, \bigcirc=5.0 \mathrm{mg} \mathrm{kg}^{-1}$ day $^{-1}, \mathrm{~N}=6-9$ ) was administered from day zero to the 14 th day of arthritis induction orally (A and $\mathrm{C}$ ) or intramuscularly (B and D). The daily hyperalgesia measurements are reported as the number of vocalizations upon 5 flexions of the tibiotarsal joints of the animals (mean \pm SEM, $N=4-6$ ). Hindpaw volumes are reported as the mean volume increase (ml) \pm SEM. For comparison, the results of hyperalgesia and edema presented by rats receiving $0.1 \mathrm{mg} \mathrm{kg}^{-1}$ day $^{-1}$ dexamethasone $(\square, \mathrm{N}=6)$ and control arthritic rats $(\mathbf{\Lambda})$ are also shown. ${ }^{*} \mathrm{P}<0.05$ compared to control arthritic rats (ANOVA t-test). 
Table 1 - Dose-dependent reduction of joint hyperalgesia and hindpaw edema presented by arthritic rats treated with dexamethasone by the oral route.

Dexamethasone or saline (control) was administered once a day orally (by gavage) to rats from day zero to the 14th day of arthritis induction ( $N=6-11$ per group). Hyperalgesia: number of vocalizations upon 5 flexions of the hindpaw tarsotibial joints of the animals (mean \pm SEM). The hindpaw edema was measured by plethysmometry and is reported as volume increase in $\mathrm{ml}$ (mean $\pm \mathrm{SEM}$ ). ${ }^{*} \mathrm{P}<0.05$ compared to paired control (ANOVA t-test).

\begin{tabular}{|c|c|c|c|c|c|c|}
\hline \multirow[t]{3}{*}{ Group } & \multicolumn{6}{|c|}{ Day after induction of arthritis } \\
\hline & \multicolumn{3}{|c|}{ Hyperalgesia } & \multicolumn{3}{|c|}{ Edema } \\
\hline & 0 & 8th & 12th & 0 & 8th & 12th \\
\hline Control & $0.20 \pm 0.04$ & $0.26 \pm 0.07$ & $0.98 \pm 0.07$ & $2.11 \pm 0.02$ & $2.11 \pm 0.01$ & $2.43 \pm 0.05$ \\
\hline \multicolumn{7}{|l|}{ Dexamethasone } \\
\hline $0.01 \mathrm{mg} \mathrm{kg}^{-1} \mathrm{day}^{-1}$ & $0.25 \pm 0.08$ & $0.11 \pm 0.06$ & $0.43 \pm 0.20^{*}$ & $2.12 \pm 0.01$ & $2.07 \pm 0.02$ & $2.17 \pm 0.02^{*}$ \\
\hline $0.1 \mathrm{mg} \mathrm{kg}^{-1} \mathrm{day}^{-1}$ & $0.28 \pm 0.08$ & $0.06 \pm 0.03^{*}$ & $0.06 \pm 0.03^{*}$ & $2.08 \pm 0.02$ & $2.05 \pm 0.02$ & $2.03 \pm 0.01 *$ \\
\hline
\end{tabular}
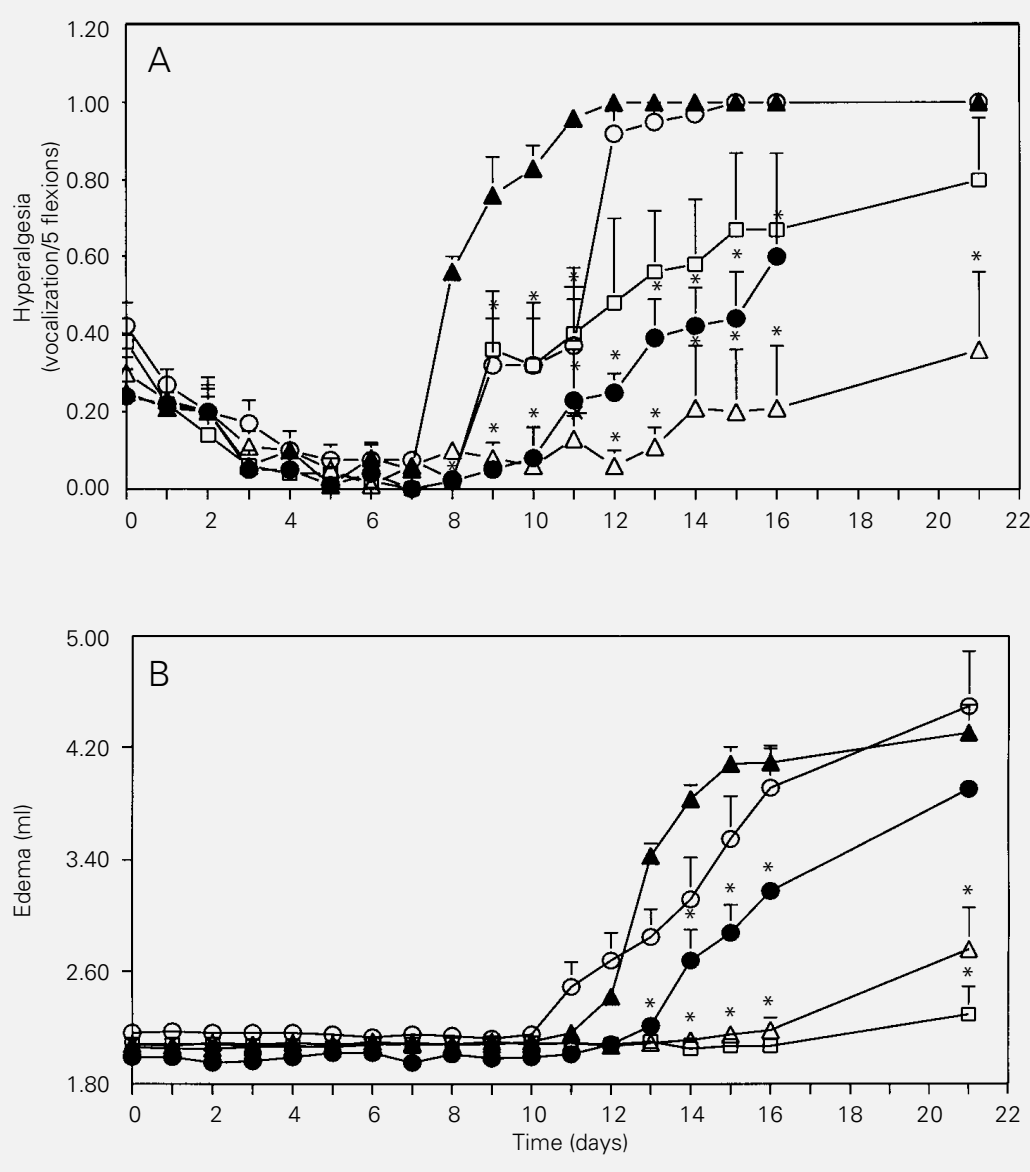

Figure 3 - Intracerebroventricular administration of cyclosporin dose-dependently reduced the hyperalgesia ( $A$ ) and edema (B) presented by arthritic rats. Cyclosporin $\left(O=1.5, \bullet=15,{ }^{a}=\right.$ $150 \mu \mathrm{g} /$ day in a $10 \mu \mathrm{l}$ volume) was administered by the intracerebroventricular route from day zero to the 14th day of arthritis induction. Control arthritic rats $(\mathbf{\Delta})$ received $10 \mu \mathrm{l}$ cremophor El (vehicle) diluted in sterile physiological saline using the same schedule. The daily hyperalgesia measurements are shown as the number of vocalizations upon 5 flexions of the tibiotarsal joints of the animals (mean \pm SEM, $N=4-7$ ). Hindpaw volumes are presented as the mean \pm SEM (in ml). For comparison, the results of hyperalgesia and edema presented by rats treated with $15 \mu \mathrm{g} /$ day dexamethasone $(\square, N=4)$ are also shown. ${ }^{*} P<0.05$ compared to animals treated with vehicle (ANOVA t-test). 
sia relapse occurred the second day after the end of treatment (data not shown). As observed for cyclosporin, a similar dose of 15 $\mu \mathrm{g} /$ day dexamethasone administered $i c v$ significantly reduced the hindpaw hyperalgesia (Figure 3A; $\mathrm{P}<0.05$, ANOVA) and completely blocked the hindpaw edema of arthritic rats (Figure 3B). However, one of the 5 animals was found dead on the last day of treatment (14th). The hyperalgesia and edema observed in arthritic animals injected icv with either saline or vehicle were not significantly different from each other.

Since the antiarthritic effect of the low doses of cyclosporin administered icv could have derived from a peripheral action, we collected systemic blood samples from those animals in an attempt to detect cyclosporin. Table 3 summarizes the CsA concentrations obtained by specific RIA in whole blood samples. The time course of CsA concentration for the oral route during the treatment with a $5-\mathrm{mg} / \mathrm{kg}$ dose showed an increase from the 8th to the 12th day of administration, whereas samples from icv-treated animals did not contain any detectable amount of the drug (Table 3). In addition, peripheral blood collected at the 12th day of treatment from animals which had been treated $4 \mathrm{~h}$ before with effective $i c v$ doses (15 or 150 $\mu \mathrm{g}$ ) of cyclosporin did not contain detectable levels of the drug.

An invariable sign of arthritis development in induced rats was the stabilization or a net decrease of their weight about the 8th day of induction (Figure 4). In contrast, arthritic rats treated orally with $5 \mathrm{mg}$ cyclosporin $\mathrm{kg}^{-1}$ day $^{-1}$ had the same profile of weight gain as control (Figure 4) or normal animals (data not shown). Different from cyclosporin, however, rats given $0.1 \mathrm{mg}$ of dexamethasone $\mathrm{kg}^{-1}$ day $^{-1}$ by the oral route significantly lost weight between the 4 th and the 12th day of arthritis. This response was not observed when dexamethasone was administered im or icv (data not shown). No other behavioral or neurological sign of toxicity was observed in cyclosporin- or dexamethasone-treated animals.

\section{Discussion}

The rat adjuvant arthritis model reproduces many of the signs and symptoms of human rheumatoid arthritis (1-4). Drugs which reduce or block the development of hindpaw edema in arthritic rats have been useful in increasing our understanding of the pathophysiology of rheumatoid arthritis and in the detection of anti-inflammatory, immu-

Table 2 - Effect of the duration of cyclosporin administration by the intracerebroventricular route on joint hyperalgesia and hindpaw edema in arthritic rats.

Cyclosporin was administered at a daily dose of $15 \mu \mathrm{g} / \mathrm{animal}$ in a volume of $10 \mu \mathrm{l}$. Control animals were injected with the same volume of vehicle $(N=5-7)$. Hyperalgesia: number of vocalizations upon 5 flexions of the hindpaw tarsotibial joints of the animals (mean \pm SEM). Hindpaw edema was measured by plethysmometry and is reported as volume increase in $\mathrm{ml}$ (mean $\pm \mathrm{SEM}$ ). ${ }^{*} \mathrm{P}<0.05$ compared to paired control (ANOVA t-test).

\begin{tabular}{|c|c|c|c|c|c|c|}
\hline \multirow{3}{*}{$\begin{array}{l}\text { Duration of } \\
\text { treatment }\end{array}$} & \multicolumn{6}{|c|}{ Day after induction of arthritis } \\
\hline & \multicolumn{3}{|c|}{ Hyperalgesia } & \multicolumn{3}{|c|}{ Edema } \\
\hline & 8th & 12th & 15th & 8th & 12th & 15th \\
\hline Control & $0.56 \pm 0.04$ & 1.0 & 1.0 & $2.07 \pm 0.01$ & $2.42 \pm 0.04$ & $4.09 \pm 0.04$ \\
\hline 15 days & $0.02 \pm 0.01^{*}$ & $0.25 \pm 0.05^{*}$ & $0.44 \pm 0.13^{*}$ & $2.01 \pm 0.12$ & $2.08 \pm 0.08^{*}$ & $2.88 \pm 0.20^{*}$ \\
\hline 8 days & $0.04 \pm 0.02 *$ & $0.82 \pm 0.08$ & 1.0 & $2.02 \pm 0.02$ & $2.22 \pm 0.05^{*}$ & $4.10 \pm 0.12$ \\
\hline
\end{tabular}


nomodulatory and analgesic effects of drugs (6,18,23-25).

In the present study, we have shown that the development of joint hyperalgesia (by the 8th day) precedes the development of hindpaw edema (12th day) following the induction of arthritis. The development of this hyperalgesia was paralleled by a weight loss compared to control animals and may reflect the increasing difficulty of the animals in reaching their food. However, a decreased appetite could also contribute to the weight loss observed since this phenomenon is an established feature of the active immune phase of arthritis in humans (26). Thus, hyperalgesia, weight loss and decreased appetite may indicate involvement of the CNS in the pathophysiology of the experimental disease in a manner similar to that observed for the human condition.

The involvement of the immune system in both human and experimental arthritis is well known. Interleukin 1 (IL-1), one of the prominent cytokines involved in the early activation of T-lymphocytes, has been de-

Table 3 - Cyclosporin (CsA) concentration in whole blood detected by specific radioimmunoassay after oral and intracerebroventricular administration to rats.

Aliquots of $50 \mu \mathrm{l}$ whole blood from all samples (internal standard-added, oral and $i c v)$ were pretreated with $950 \mu \mathrm{l}$ methanol. Aliquots of the methanolic supernatant $(50 \mu \mathrm{l})$ were prediluted with buffer $(500 \mu \mathrm{l})$ and incubated with $\left[{ }^{3} \mathrm{H}\right]-\mathrm{CsA}$ and the specific monoclonal antibody for $2 \mathrm{~h}$ at $4^{\circ} \mathrm{C}$. Bound and free CsA were separated at $4^{\circ} \mathrm{C}$ after the addition of a charcoal suspension and centrifugation. Bound activity was measured in the supernatant by liquid scintillation counting (RackBeta, Beckaman). Data are reported as mean $\pm \mathrm{SD}$ for $\mathrm{N}$ animals in each group. Measurements were made on the 8th and 12th days following oral or icv administration, and in additional groups on the 12th day ( 15 and $150 \mu \mathrm{g} /$ day), $4 \mathrm{~h}$ after icv cyclosporin administration. N.D. $=$ Not detectable.

\begin{tabular}{|c|c|c|c|}
\hline \multirow[t]{2}{*}{ Route and dose } & \multicolumn{3}{|c|}{ CsA concentration in whole blood $(\mathrm{ng} / \mathrm{ml})$} \\
\hline & 8th day & 12th day & 12th day \\
\hline \multicolumn{4}{|l|}{ Oral } \\
\hline $5 \mathrm{mg} \mathrm{kg}^{-1}$ day $^{-1}$ & $170 \pm 28(N=5)$ & $640 \pm 161(N=4)$ & - \\
\hline \multicolumn{4}{|l|}{$i c v$} \\
\hline $15 \mu \mathrm{g} / \mathrm{day}$ & N.D. $(N=6)$ & N.D. $(N=6)$ & N.D. $(N=2)$ \\
\hline $150 \mu \mathrm{g} / \mathrm{day}$ & N.D. $(N=5)$ & N.D. $(N=3)$ & N.D. $(N=2)$ \\
\hline
\end{tabular}

tected in the blood and joint cavities of arthritic persons as well as in adjuvant-injected rats (27-29). IL-1 induces T-lymphocyte activation and proliferation through the release of another cytokine, IL-2 (27,30), which, when injected intra-articularly into the rat knee joint, is also able to induce mechanical hyperalgesia (31). The diseaseinduced release of IL-1 may thus activate immunocompetent cells with a consequent release of IL-2 into the joints, thereby explaining the articular hyperalgesia observed in arthritic rats in this study. The presence of IL-1 itself in the knee joint could also account for some of the hyperalgesia detected since this cytokine is able to induce hyperalgesia in the rat paw (32) and in the rat knee joint (29).

In accordance with the above hypothesis, immunosuppressive drugs such as cyclosporin, which inhibit the release of various cytokines including IL-2 by activated lymphocytes (33), should be able to inhibit the development of hyperalgesia in arthritic rats. Indeed, cyclosporin was reported to alleviate the pain associated with arthritis in human trials $(34,35)$. In the present study, we demonstrated that the daily oral orim administration of cyclosporin blocked the development of hyperalgesia and edema in arthritic rats in a dose-dependent manner. While the anti-edematogenic effect remained blocked throughout the period of observation (22 days), even after treatment was stopped, the analgesic effect of oral cyclosporin was clearly reversed within two days after drug withdrawal. These results suggest that a) continuous presence of cyclosporin is essential in order to reduce the development of joint hyperalgesia and that b) different mechanisms underlie the appearance of joint hyperalgesia and hindpaw edema in this model.

Cyclosporin, an undecapeptide with a pronounced hydrophobic character (36), is considered not to cross the blood-brain barrier (BBB) to any significant extent following systemic administration in man and mice 
$(11,37)$. When cyclosporin was injected into the CNS of adjuvant-induced rats, it was able to produce the same antiarthritic effects observed when systemically administered. Since cyclosporin does not cross the BBB, one must conclude that this antiarthritic effect was exerted directly through one or more preexisting sites in the CNS which were reached upon injection. This conclusion is supported by the 5- to 50-fold lower dose of cyclosporin required to produce this antiarthritic effect compared to the doses normally administered systemically to animals or humans. The antiarthritic response observed with a shorter schedule of cyclosporin or a low dose of dexamethasone injected by the same route in arthritic rats gives further support to this view. However, dexamethasone centrally or systemically administered has shown to be unexpectedly more toxic than cyclosporin administered by the same route in arthritic rats, despite the central clinical side effects reported during conventional therapy with cyclosporin (38). Dexamethasone-treated animals, especially those orally treated, showed a pronounced weight loss, indicating a probable drug-induced damaging action on the gastrointestinal tract. In addition, the $i c v$ administration of an effective anti-arthritic dose of dexamethasone resulted in the death of one animal. Together, the present data support the view that dexamethasone is more toxic to the animals than cyclosporin.

The concept of 'immunological privilege' established for the CNS (39) has been challenged (40). In addition, a highly regulated communication between the brain and the immune system via the cervical lymphatics and BBB has been reported (41). In the present study we provide evidence showing that the central administration of effective low doses of cyclosporin did not reach the periphery, since no detectable levels $(<0.001 \%)$ were demonstrable in the systemic blood collected from the animals following 8 or 12 days of treatment, or after

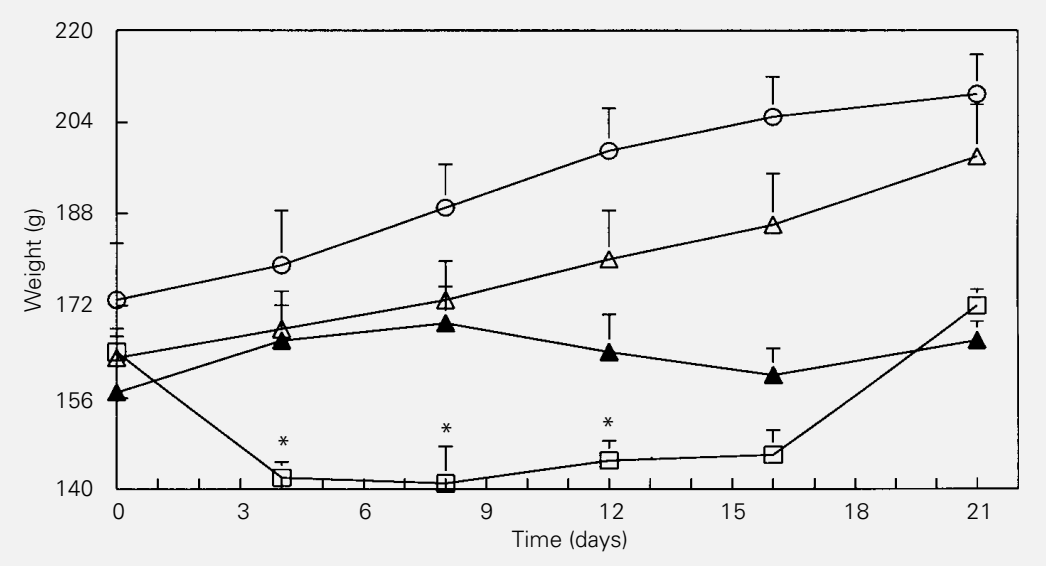

Figure 4 - Changes in the weight (g) of arthritic rats treated systemically with cyclosporin and dexamethasone. The animals were weighed every four days from day zero to the $21 \mathrm{st}$ day after induction of arthritis. Cyclosporin ( ${ }^{\mathrm{a}}, 5 \mathrm{mg} \mathrm{kg}^{-1}$ day $\left.^{-1}, \mathrm{~N}=6\right)$ or dexamethasone $(\square$ $0.1 \mathrm{mg} \mathrm{kg}^{-1}$ day $^{-1}, \mathrm{~N}=6$ ) was administered orally up to the 14 th day of arthritis induction. The weight of rats injected with mineral oil without adjuvant $(O, N=4)$ and of control arthritic rats $(\mathbf{\Lambda})$ is also shown. ${ }^{*} \mathrm{P}<0.05$ compared to control arthritic rats (ANOVA $t$-test).

acute $i c v$ administration of effective (antiarthritic) doses. Consistent with an antiarthritic effect induced by cyclosporin in the CNS is the fact that neurons are a rich source of cyclophilin (30), the cytosolic receptor for cyclosporin, whose interaction could ultimately lead to inhibition of IL-2 production by them. As yet, however, no definite link between the cellular action of cyclosporin at the neuronal cyclophilin level and its antiarthritic effect in the CNS has been established. Other cell lines such as the specialized macrophages present in the microglia could eventually contribute to the observed cyclosporin-induced antiarthritic effect in the rat CNS.

In summary, the results of the present study show that joint hyperalgesia precedes the development of hindpaw edema in arthritic rats. Daily systemic (oral or intramuscular) administration of cyclosporin dosedependently reduced both hyperalgesia and edema. Unexpectedly, a 5 to 50-fold lower dose of cyclosporin administered icv also reduced the hyperalgesia and edema, thus demonstrating for the first time a central antiarthritic effect for this drug. Although 
the precise central site (or sites) for the observed action was not determined, we suggest that the development of new formulations for delivery of cyclosporin to the CNS of rodents may provide a similar antiarthritic effect. This would be of great benefit for the long term immunosuppression of selected cases of human rheumatoid arthritis and related conditions, since it would avoid the side effects frequently associated with systemic cyclosporin therapy.

\section{Acknowledgments}

The authors gratefully acknowledge Dalton L. Ferreira-Alves (MD) and Maria Ap. K.F. Tatsuo (PhD) for their advice during the study. We also wish to thank Mr. Webster G.P. Dos Reis for excellent technical assistance.

\section{References}

1. Owen RT (1980). Adjuvant induced polyarthritis - an overview. Methods and Findings in Experimental and Clinical Pharmacology, 2: 199-204.

2. Pearson CM (1956). Development of arthritis, periarthritis and periostitis in rats given adjuvants. Proceedings of the Society for Experimental Biology and Medicine, 91: 95-101.

3. Pearson CM \& Wood F (1963). Studies of arthritis and other lesions induced in rats by the injection of mycobacterial adjuvant. American Journal of Pathology, 42: 93-95.

4. Stoerck HD, Bielinski TC \& Budzilovich $T$ (1954). Chronic polyarthritis in rats injected with spleen in adjuvants. American Journal of Pathology, 30: 616A.

5. Van Arman GC (1976). Pathway to adjuvant arthritis. Federation Proceedings, 35: 2442-2446.

6. Colpaert FC, Meert T, De Witthand P \& Schmitt P (1982). Further evidence validating adjuvant arthritis as an experimental model of chronic pain in the rat. Life Sciences, 31: 67-75.

7. Pearson CM \& Chang TY (1977). The contribution of adjuvant arthritis to the recognition of antirheumatic drugs. In: Dumonde DC \& Jasane JK (Editors), Recognition of Anti-Rheumatic Drugs. MTP Press Limited, Lancaster, 229-239.

8. Binderup L (1983). Decreased T-suppressor cell activity in rats with adjuvant arthritis. Annals of the Rheumatic Diseases, 42: 693-698.

9. Waksman BH, Pearson CM \& Sharp JT (1960). Studies of arthritis and other lesions induced in rats by injection of mycobacterial adjuvant. II. Evidence that disease is a disseminated immunologic response to exogenous antigen. Journal of Immunology, 85: 403-417.
10. Carlson RP, Hartman DA, Tomcheck LA, Walter TL, Lugay JR, Calhoun W, Sehgal SN \& Chang JY (1993). Rapamycin, a potent disease-modifying antiarthritic drug. Journal of Pharmacology and Experimental Therapeutics, 266: 1125-1138.

11. Faulds D, Goa KL \& Benfiel P (1993). Cyclosporin: a review of its pharmacodynamic and pharmacokinetic properties and therapeutic use in immunoregulatory disorders. Drugs, 45: 953-1040.

12. Morris WR (1992). Rapamycins: antifungal, antitumor, antiproliferative, and immunosuppressive macrolides. Transplantation Reviews, 6: 39-87.

13. Sigal NH \& Dumont FJ (1992). Cyclosporin A, FK-506, and rapamycin: pharmacological probes of lymphocyte signal transduction. Annual Review of Immunology, 10: 519-559.

14. Burnstein KL \& Cidlowski JA (1989). Regulation of gene expression by glucocorticoids. Annual Review of Physiology, 51: 683-699.

15. Sternberg EM \& Wilder RL (1993). Corticosteroids. In: McCarty DJ and Koopman WJ (Editors), Arthritis and Allied Conditions. Vol. I. Lea \& Febiger, Philadelphia, 665-682.

16. Capetola JR, Shriver AD \& Rosenthale EM (1980). Suprofen, a new peripheral analgesic. Journal of Pharmacology and Experimental Therapeutics, 214: 16-23.

17. Pircio AW, Fedele $C T$ \& Bierwage ME (1975). A new method for the evaluation of analgesic activity using adjuvant-induced arthritis in the rat. European Journal of Pharmacology, 31: 207-215.

18. Tatsuo MAKF, Carvalho WM, Silva CV, Miranda AEG, Ferreira SH \& Francischi JN (1994). Analgesic and antiinflamatory effects of dipyrone in rat adjuvant arthritis model. Inflammation, 18: 399-405.
19. Lemaire M, Pardridge WM \& Chaudhuri G (1988). Influence of blood components on the tissue uptake indices of cyclosporin in rats. Journal of Pharmacology and Experimental Therapeutics, 244: 740-743.

20. Konig JFR \& Klippel RA (1974). The Rat Brain: A Stereotaxic Atlas of the Forebrain and Lower Parts of the Brain Stem. Krieger Publishing Co. Inc., New York.

21. Johnston A, Marsden JT \& Holt DW (1989). The continuing need for quality assessment of cyclosporin measurement. Clinical Chemistry, 35: 1309-1312.

22. Ball PE, Munzer $H$, Keller HP, Abisch E \& Rosenthaler J (1988). Specific $\left[{ }^{3} \mathrm{H}\right]$ radioimmunoassay with a monoclonal antibody for monitoring cyclosporin in blood. Clinical Chemistry, 34: 257-261.

23. Connolly KM, Stecher VJ, Danis E, Pruden D \& Jandlabrien T (1988). Alteration of interleukin 1 production and the acute phase response following medication of adjuvant arthritic rats with cyclosporin A or methotrexate. International Journal of Immunopharmacology, 10: 717-728.

24. Del Pozo E, Elford P, Perrelet R, Graeber M, Cazez PJ, Modrowski D, Payne T \& Mackenzie AR (1992). Prevention of arthritis by cyclosporine in rats. Seminars in Arthritis and Rheumatism, 21: 23-29.

25. Jaffe BD, Kerr JS, Jones EA, Giannaras JV, McGowan M \& Ackerman NR (1989). The effect of immunomodulating drugs on adjuvant-induced arthritis in Lewis rats. Agents and Actions, 27: 345-346.

26. Cunningham Jr ETC \& De Souza EB (1993). Interleukin 1 receptors in the brain and endocrine tissues. Immunology Today, 14: 171-176.

27. Dinarello CA (1991). Interleukin 1. In Thomson AW (Editor), The Cytokine Handbook. Academic Press, San Diego, 47-82. 
28. Eastgate JA, Symons JA, Wood NC, Grilinton FM, Giovani FS \& Duff GW (1988). Correlation of plasma interleukin 1 levels with disease activity in rheumatoid arthritis. Lancet, 2: 706-709.

29. Nouri AME, Panayi GS \& Goodman SM (1984). Cytokines and the chronic inflammation of rheumatic disease. I. The presence of interleukin-1 in synovial fluids. Clinical and Experimental Immunology, 55: 295-302.

30. Pugh-Humphreys RGP, Woo J \& Thomson AW (1991). Cytokines and their receptors as potential therapeutic targets. In: Thomson AW (Editor), The Cytokine Handbook. Academic Press, San Diego, 357-386.

31. Davies AJ \& Perkins MN (1994). The involvement of bradykinin $B_{1}$ and $B_{2}$ receptor mechanisms in cytokine-induced mechanical hyperalgesia in the rat. British Journal of Pharmacology, 113: 63-68.

32. Ferreira SH, Lorenzetti BB, Bristow AF \& Poole S (1988). Interleukin-1 beta as a potent hyperalgesic agent antagonized by a tripeptide analogue. Nature, 334: 698700 .
33. Rao A (1994). NF-ATp: a transcription factor required for the co-ordinate induction of several cytokine genes. Immunology Today, 15: 274-281.

34. Tugwell P, Bombardier C, Gent M, Bennee KJ, Bensen WG, Carette S, Chalmers A, Esdaile JM, Klinkhoff AV, Kraag GR, Ludwin D \& Roberts RS (1990). Low-dose cyclosporin versus placebo in patients with rheumatoid arthritis. Lancet, 335: 1051-1055.

35. Yocum DE, Wilder RL, Dougherty $S$, Klippel JH, Pillemer S \& Wahl S (1990). Immunologic parameters of response in patients with rheumatoid arthritis treated with cyclosporin A. Arthritis and Rheumatism, 33: 1310-1316.

36. Wutrich K, Von Freyberg B, Weber C, Wilder G, Traber R, Widmer H \& Braun W (1991). Receptor-induced conformation change of the immunosuppressant cyclosporin A. Science, 254: 953-954.

37. Fazakerley JK \& Webb HE (1985). Cyclosporin, blood-brain barrier, and multiple sclerosis. Lancet, 19: 889-890.
38. Groen PC, Aksamit ALJ, Rakela J, Forbes GS \& Krom RAF (1987). Central nervous system toxicity after liver transplantation. The role of cyclosporin and cholesterol. New England Journal of Medicine, 317: 861-866.

39. Widner $H$ \& Brundin $P$ (1988). Immunological aspects of grafting in the mammalian central nervous system. A review and speculative synthesis. Brain Research Reviews, 13: 287-324.

40. Owens T, Renno T, Taupim V \& Krakowski $M$ (1994). Inflammatory cytokines in the brain: does the CNS shape immune responses? Immunology Today, 15: 566571.

41. Cserr HF \& Knopf PM (1992). Cervical lymphatics, the blood-brain barrier and the immunoreactivity of the brain: a new view. Immunology Today, 13: 507-512. 